\title{
Una poética del género: la escritura mistraliana en Niña Errante
}

\section{Gender Poetics: Mistralian Writing in Niña Errante}

\author{
Eugenia Brito \\ Facultad de Artes de la Universidad de Chile \\ eugeniabritoastrosa@gmail.com
}

\section{Resumen}

La siguiente ponencia consiste en la indagación sobre la escritura y el sujeto en proceso de las cartas que constituyen el texto de Niña Errante, específicamente en los núcleos metafóricos en los que aparece la conflictiva manera con que la escritora significó tanto su ficción genérica a lo largo de sus textos poéticos como la o las formas con las que semantizó el mundo simbólico de la mujer dentro del mundo literario latinoamericano.

Palabras clave: poética mistraliana, sujeto, escritura, genero, mundo chileno.

\section{Abstract}

The following paper is an inquiry into the writing and the subject in process of the letters that constitute the text of Niña Errante, specifically in the metaphorical cores showing the conflictive way in which the writer signified her gender fiction throughout her poetical writings, as the ways in which she semanticized the symbolical world of women inside the Chilean and Latino American world.

Keywords: Mistralian Poetics, Subjet, Writing, Genre, Chilean World. 
Las feministas han señalado con bastante agudeza (Gayle Rubin, Judith Butler) la inestabilidad del concepto de género y de la noción de género de la mujer, que recorre toda la historia "occidental", para hablar de un universo que aparece entremezclado en la configuración de la nación, la ciudadanía, la historia de las ideas y en toda la articulación del discurso cultural y político de nuestro país. Mientras la masculinidad se configura de manera sólida y homogénea, a pesar de los micro movimientos existentes hoy con el nombre de "masculinidades en crisis". Por muy fragmentado y estallado que esté el concepto de sujeto masculino, no se acerca para nada a los bordes periféricos de las crisis de las mujeres, empobrecidas e invisibilizadas en los aparatos de poder. Siempre sujetas a la voz de un padre que, militante o caudillo, líder de hoy o de ayer, muchas de ellas- las más se mantienen en el refugio del trabajo remunerado o en trabajos públicos ausentes de la formación de la política chilena contemporánea.

En la conocida antología Womens Writing in Latin America, la escritora y crítica argentina Sylvia Molloy señala en su lúcida Introducción a la Segunda Parte que, a su parecer un rasgo que define la escritura de la mujer sería una dislocación en el orden del ser. ("a dislocation in order to be"). Este rasgo podría ser el impulso principal detrás de sus escrituras. Cita dos ejemplos: Mistral: "Estoy donde no estoy" ("Niño mexicano") y Pizarnik, años después: "Escribir con palabras de este mundo que un barco partió de mí llevándome”.

Las Cartas de Gabriela Mistral a Doris Dana son ese espacio textual en el que a través de la correspondencia de la poeta a la mujer que la acompañó durante la última década de su vida, desplaza su escritura por una zona de su ser en que de manera clara abre algunos de los enigmas que acompañaron curiosamente no sólo su producción literaria sino también su vida, la gran producción de todo humano. Vida en la que movilizó de manera decidida los signos fijos de la construcción identitaria asignada a la mujer en todos los ámbitos de la cultura.

Pocos seres en Chile han levantado tanta polémica en el discurso público que ella generó, así como en el crítico y el académico, desde el cual se ha leído de distintas formas su producción. Hay preguntas que la acompañaron desde que publicó sus primeros poemas, "Sonetos de la Muerte", durante su permanencia en Chile, sus viajes, sus epistolarios. Incluso ahora, a más de 60 años de su muerte, en Estados Unidos, suscita debates y relecturas, abriendo grandes aparatajes críticos. Aunque también aparecen apasionadas pero cegatonas defensas, como por ejemplo la escrita por Hernán Ortega, en el Archivo de Chile, en el año 2006.

Para seguir con la cita a Sylvia Molloy, esta "dislocación del ser" citaría la dificultad de la mujer para sortear los lugares transitados por la cultura, los "estereotipos" de la "esposa y madre amante". Son éstos lugares privados y periféricos, por definición, ecos del modelo masculino así como reiteración del sistema de poderes que desde el acceso a la palabra hasta el ingreso a la sexualidad y hasta la vejez, programan al cuerpo de la mujer o de las mujeres. De acuerdo a Homi Bhabha, la estrategia del dominador consiste en invisibilizar a su otro, el/ la subalterno/a, lo que explicaría la 
desrealización de la que hablara Mistral en su poema "Electra en la Niebla" o Bombal en su conocido texto La Ultima Niebla. La que finaliza en la nada, la privación del ser en la cultura occidental. Coincido con Raquel Olea, en su texto Como traje de fiesta, en su aseveración de que Gabriela Mistral ha sido

\footnotetext{
atrapada en el nombre de madre de Chile y de poeta nacional. La representación resguarda su trascendencia social, la permanencia de su sentido en el tiempo, preservando a su vez, celosamente, cualquier forma de expansión hacia aquello que le ha sido sustraído. La diferencia desplazada del nombre oficial, la otredad acallada, el extrañamiento innombrado- en su escritura como en su biografía- es un llamamiento a la lectura crítica y a la escritura biográfica a hacerse cargo de nuevos interrogantes y operaciones de lectura que permitan desmantelar la clausura operada por la simbolización oficialmente legitimada (23).
}

Considero que la figura de la Mistral, por ser una mujer pública y además una mujer visible, la manera de verla fue a través de los lugares comunes con que se ve generalmente la vida de una mujer, como un guión inadecuado, limitado y torpe.

Se la consideró amante frustrada (de un tal Romelio Ureta, a quien no conoció), madre frustrada también por no tener hijos sin pensar que la Nóbel jugó con los únicos signos de que disponía la cultura de su época para ser considerada y respetada por los poderes de su tiempo. Como bien señala Raquel Olea, una selección restringida de su corpus, los poemas amorosos y los poemas infantiles, se dieron a conocer desde la escuela y la prensa alcanzando el dominio público. Tala, su libro mayor y Lagar no se leyeron de manera analítica, a excepción de la enseñanza universitaria especializada.

Es en esos ámbitos desde donde en los años 80 surge la propuesta por una lectura más completa de la producción mistraliana, desde el punto de vista del género, la sexualidad y los debates teóricos propios de la cultura y literatura hispanoamericana. Mistral es para Jorge Guzmán (Diferencias Latinoamericanas, 1984) el significante de la mujer chilena mientras que para Marchant es un árbol-madre, lugar fundamental que permea la escritura de una nación desolada (durante la dictadura).

Los siguientes años han sido claves para desarticular los estereotipos sobre Mistral: Adriana Valdés, Kemy Oyarzún, Ana Pizarro, Jaime Concha, Jorge Etcheverry, Grinor Rojo, Raquel Olea, Jean Franco, Naín Nómez y otros más han señalado las múltiples formas que recorren los sentidos de sus textos.

La razón del enigma mistraliano es el espesor material de los significantes que portan su ser y su producción cultural; el de una mujer que rebasó todos los lugares, desde la patria hasta la Antipatria, como lo sugiere Jean Franco. Desde la razón y la locura hasta la loca razón, desde la no maternidad hasta la maternidad de humo. Desde la categoría genérica femenina a la masculina, en las cartas que nos ocupan hoy: las de Niña Errante. Cartas a Doris Dana, su última compañera, norteamericana, estudiante de un postgrado en Literatura en Nueva York, joven de 28 años cuando Mistral la conoce dando una conferencia sobre Thomas Mann, en Barnard College. 
Las cartas hoy son consideradas como producciones discursivas del mismo valor que otras producciones canónicas, como la novela, ensayo, poesía. Ha sido Derrida quien a través de su obra ha establecido la identidad de estatus de las notas, epígrafes, cartas y conversaciones con respecto a libros, artículos y aún obras completas. Pues consideró que las cartas o las notas son parte de un proceso idéntico de escritura, al igual que la obra de un autor consolidado, como ocurre en el caso de Sigmund Freud, analizado en el texto La Tarjeta Postal.

En Chile, el escritor y crítico Leonidas Morales, quien en su libro La Escritura de al lado. Géneros Referenciales da un lugar cultural y simbólico a estos objetos, señala: "géneros discursivos "referenciales" llamo aquí a aquellos donde, al revés de lo que ocurre en los ficcionales, como la novela, autor, sujeto de enunciación ( o "narrador”) coinciden: son el mismo. Hablo de géneros como la carta, el diario íntimo, la autobiografía, las memorias, la crónica, el ensayo o géneros periodísticos como la entrevista, biográfico"

En las Cartas de Gabriela Mistral queremos establecer una cierta distancia con lo que Morales da por sentado: "el autor, el sujeto de enunciación coinciden con el / la yo de los enunciados”. En Niña errante, la escritora se refiere a sí misma como:

Parece que tú ignoras aún que a mí me viene una especie de borrachera de amargura de pronto, algo como una purga infernal que me cae a las entrañas y que me da una agonía sin sangre y sin llanto, es decir, sin alivio. Aquel grupo de fotos unidas por un elástico, me produjo eso. Y yo no debí escribirte en tal estado de ánimo, pero soy arrebatado, recuérdalo y colérico y TORPE, TORPE. Por favor, no vuelvas nunca nunca a sufrir así, a padecer por mi culpa. Sabe que de una vez, padeciendo así, me das tú una enorme vergüenza de mí mismo (54).

La zona de enunciación de la escritura de esta carta elabora un relato de sí misma y de sus estados psíquicos: la purga infernal, que sostiene, refiriéndose a sus "entrañas" como la zona de sus emociones eróticas y afectivas, al shock emocional que recibe al ver algunas fotos. Y se refiere a sí misma en masculino: soy arrebatado y colérico. Más adelante, dice "me das tú una enorme vergüenza de mí mismo".

Este tránsito de lo femenino a lo masculino es una de las características del epistolario e indica un punto de fuga de la escritura mistraliana. Llamará la atención del desprevenido lector chileno, acostumbrado a leer en sus producciones una concordancia de la escritura con un sujeto mujer formalmente reconocible con el yo tradicionalmente estereotipado de la mujer "chilena": esposa y madre. En ese sentido, la correspondencia entre el ser que fue Mistral y el que aparece en su escritura es discontinua, por la capacidad de su escritura de proponer una multiplicidad de seres que la nombran, en una galería de diferentes metáforas y metonimias que la duplican, la restan o la alternan en inagotables metamorfosis. 
Pero Mistral no sorprende a sus lectores más avezados. Está en desacuerdo íntimo con ese yo, no calza con el modelo "femenino" tradicional, vale decir, fijado a los rígidos códigos con los que se alinea la construcción de la mujer, sumisa, pasiva, receptiva frente a la capacidad pensante, activa y creadora establecida para el hombre. Mistral no ingresa a ese modelo más que en una negociación de su mundo simbólico, en que ella tuerce esos contenidos poco a poco; pasando desde la mujer dolorosa, la "viuda", como diría Nicanor Parra, de los "Sonetos de la Muerte" a la fundadora de un mundo nuevo, particularmente en Tala y en Lagar, como hacedora de una nueva forma de pensar y construir el mundo latinoamericano.

En el poema Tala de Gabriela Mistral aparece un conjunto de textos denominado "Locas mujeres", en los que la artista expresa con el nombre de "loca" los estados de ansiedad y de angustia con que vivió su mundo. A Mistral le quedan tres años de vida (muere en 1957) cuando publica su poemario Lagar, en 1954.

No quiero señalar con esto que en la disyuntiva de género se encuentre el total de la compleja mujer que fue Mistral. De lo que hablo es de una problemática íntima y dolorosa impresa en el ser de la artista, vivida entre el ser y el deber ser, entre las fronteras locales y las del mundo internacional que ella constituyó en México, Puerto Rico, Cuba, Italia, Estados Unidos; entre ese debate que era en realidad un imperativo social. El guión de la subjetividad mistraliana era un universo hecho de paisajes y personas; que de Chile amó básicamente el lugar en que nació, el Valle de Elqui, del que guardó ciertos signos; el principal, la madre y su recuerdo, como también su medio hermana, por cierto, fue tributaria del imaginario andino que constituyó en ese lugar con sus arcaísmos, su flora, fauna, su vegetación, pero no sólo de él, también de los países latinoamericanos en los que habitó, como México y Puerto Rico, entre otros. Mistral no reconoce fronteras en la expresión de su ser extraordinariamente sensible y también hábil en su producción literaria, la que cuidó con esmero. A ese imaginario nuclear se superponen las imágenes de los países que conoce en los viajes. Por lo tanto, es sofocante para Mistral ya desde joven la limitación que la concepción de mujer latinoamericana impuso a la artista: el deber de responder sobre todo al matrimonio y la maternidad.

La escritura mistraliana con la figura de la "loca", que se reitera desde las Historias de Loca hasta "Locas Mujeres" conforma ese plus simbólico que le sobra a todo estereotipo, rígido y estrecho: la loca es la negación al control, la errancia por sobre lo rígido, la pluralidad que se niega a la linealidad que sobre la mujer impone el cristianismo y el catolicismo en particular, omite y condena a la mujer a una existencia reprimida, llena de límites. De acuerdo a ese control, sin embargo, Mistral, que profesara esa fe, se detiene en la imagen de la "mujer sola" y "estéril", a pesar de sus textos en los que se hace madre de América, ingresando al éxtass de la oración, como "peña arrobada”, como señala en "Cordillera”. 
La figura de la "extranjera", título de uno de sus poemas, es otro de los formatos que ella emplea para poner distancia sobre el ojo censurador de los hombres y/o mujeres de su país. Al mismo tiempo su identificación con un grupo de mujeres de la Biblia (Raquel, Sara) es parte de la configuración de este dilema. Las hebreas fueron estructuradas por férreos mandatos patriarcales. Mientras que las trágicas Electra y Antígona emergen en su poética como víctimas de las tragedias desencadenadas por la lujuria y/o la torpeza masculina. En Niña Errante nombra ese estado de su ser como purga infernal, en una metáfora de sus dilemas afectivos y existenciales.

A lo largo del Epistolario, Gabriela habla de su soledad: la preocupa su trabajo, se cansa de las relaciones sociales que debe mantener por su trabajo diplomático, no encuentra calma nunca, vigila su trabajo poético y diplomático, como también se preocupa de sus posesiones, habidas como renta.

La "locura" o extrañeza de Mistral sería esta gran despertenencia a los códigos culturales nacionales, y al estereotipo de la mujer. Esa reserva simbólica asignada al rol, un espacio restringido y limitado para la escritora y la escritura, fue el modo de expresarlo. No una escritura simple, sino una puesta en jaque a la cultura local, a las fronteras mentales de la patria. Es hacia ese "otro lugar" al cual como utopía navegan sus intransables signos.

¿Qué sujeto construye Mistral en esas Cartas, tituladas Niña Errante?

Son de manera temprana una crítica y cuestionadora mirada al género, tomado 40 años antes ya como "cárcel", pues se entiende como "fugitiva", implicando su salida del país, de sus instituciones y del discurso dominante. Más adelante dice: “Tú no ignoras que yo soy un enfermo, pero sabes vagamente que yo soy un alma padecida que en cuanto quede sola se hunde en una especie de nada, de "nihil". Cuando no pasa algo peor; al estado de angustia pura" $(212)^{1}$.

Esta manera de entenderse como "enfermo", un doliente aquejado de problemas es nueva en la correspondencia mistraliana, en que la enfermedad nombra el dolor, lo cita, dolor de género, aquella insatisfacción que paga con el cuerpo haciendo eco de la histeria.

Si leemos los signos emitidos por la poeta en esta carta, notaremos que su autorepresentación negativa, como enfermo o "alma padecida", sola, nihilista una posición depresiva de la poeta sometida a la mirada pública, que conoce de manera desplazada y elíptica la mujer que escribía.

Según Butler:

el problema del sujeto es fundamental para la política, pues los sujetos jurídicos siempre se construyen mediante ciertas prácticas excluyentes que, una vez terminada la estructura jurídica de la política, no se perciben. En definitiva, la construcción política del sujeto se realiza con algunos objetivos legitimadores y excluyentes, y

$1 \quad 16$-17 de Junio de 1950. 
estas operaciones políticas se esconden y naturalizan mediante un análisis político en el que se basan las estructuras jurídicas. El poder jurídico produce lo que afirma sólo representar; así, la política debe preocuparse de esta doble cara del poder, la jurídica y la representativa. (Butler 5)

El concepto de "género", la interpretación cultural de sexo implica una identidad común, puesto que el género no siempre - dice Butler- se construye de forma coherente o consistente con determinados contextos específicos, de raza, religión, y otras variables regionales y sexuales. La representación de un sujeto tiene sentido cuando no suponga nada con respecto al sujeto de las mujeres.

Si estamos de acuerdo con Butler en que el género es el medio discursivo cultural a través del cual una naturaleza sexuada se forma y establece como prediscursivo, anterior a la cultura, una superficie políticamente neutral sobre la cual actúa la cultura, debemos considerar también que la noción de género es una noción que cita al sexo, y que el sexo marcado por la ley es el masculino, y el sexo femenino es el únco género existente.

Las cartas de Mistral son pues la expresión misma de la fuga, en el sentido deleuziano, de que desde su cuerpo construye la máxima escultura de la otredad, más allá de su género, más allá de todas las constricciones binarias, fundó en su carne un estilo doloroso: la mujer maestra, adusta, la Anti Matriarca y también, la lesbiana: Sólo que ese lado, el "tercer lado", no fue visible para la cultura de la época.

Si Mistral se considera "fugitiva", es en verdad de la prisión de lo "femenino", único género marcado y dominado por el masculino, que coincide con lo universal, por lo tanto, es del lugar o lugares culturales y convencionales desde donde se la oprime, de donde se arranca, y por eso elabora desde su presencia corporal la densidad de su imagen. Traspasa el género marcado, reteniendo del modelo mariano la matriz dolorosa, pero se ancla en una "huella" de la madre, la "maestra", la asistenta que auxilia a los niños en el aprendizaje social de la cultura, es decir es bajo ese signo que a Mistral se la domestica, ignorando su enorme talento.

Sin embargo, la paradoja es que ese estereotipo, solidario en principio a la madre, proporciona a Mistral una clave para alejarse del modelo de la mujer casada, que no era conveniente a ella, en tanto, desde la mirada de la época, que imponía la mujer intuitiva y no con capacidades intelectuales como las desarrolladas por la escritora, y también el modelo de la maestra, le permitía adquirir saberes para desarrollarse en el campo cultural, lo que elaboró más tarde a través de sus cartas, recados y escritos presentados en distintas instituciones.

Sustituyó también el modelo de madre por el de madre simbólica, en el cual Chile se consideraba un país postcolonial, mestizo y pobre, necesitado de una madre masculina fuerte y capaz de gestionar con brillantez su lugar en el Primer Mundo. La poeta logró con amplitud ese encargo en su escritura. 
Gracias a estas Cartas, se abre de manera nítida algo que ya se hacía presente en la poética mistraliana, su performática de género. Si la poeta tuvo que hacer transformaciones interesantes para paliar lo angosto de la concepción de mujer que complejizó su vida de manera dramática, hay que decir que estas transformaciones poéticas dejaban siempre una zona angustiosa: "la niebla", "el vacío" del que habla en sus cartas a Doris Dana así como en sus poemas, son el precio que ella debió pagar por su rebeldía.

No quiero decir que Mistral estudiara de antemano ensayos corporales o escriturales para emerger con sus textos y su postura adusta y seria en la sociedad de su tiempo, sino más bien estos textos emergieron como una protesta y una propuesta poética en la que se juegan el simulacro y el dolor en un mismo tejido corporal; quiero decir que ambos están disputándose la emergencia mistraliana.

Para Butler, el género no es sino una puesta en escena de una condición que se practica, se constituye como performance. Para ella, la fuerte demanda de la opresión heterosexual exige una performance demasiado rígida que termina por angustiar al ser humano, en apretadas máscaras del yo, mientras en su mundo interno subyace el tejido melancólico de una relación más liberada con el propio sexo. Finalmente, como arguye Butler, es desde la ideologización de la matriz como "indeterminada y neutra" que comienza el trabajo de la cultura falologocéntrica para despolitizar y privar de su acceso al mundo simbólico a la mujer y a la madre.

Para Monique Wittig, "la ficción del sexo habría sido puesta en circulación por el sistema de heterosexualidad obligatoria, para ceñir la identidad en la heterosexualidad. La homosexualidad ofrecería la posibilidad de destruir la categoría de sexo. La proliferación de los placeres de índole no reproductiva echaría por tierra la economía erótica de la heterosexualidad. El cuerpo lesbiano puede leerse como una lectura invertida de "Tres ensayos de una teoría sexual" de Freud."(Butler, 1990).

Para Lacan, el sujeto masculino es una construcción ficticia elaborada por la ley que prohíbe el incesto y dictamina un desplazamiento infinito de un deseo heterosexualizador. Lo femenino nunca es una marca de sujeto; lo femenino no podría ser un atributo de género, más bien, lo femenino es la significación de la falta, significada por lo simbólico, la Ley del Padre. El tabú del incesto, que aleja el hijo de la madre y de este modo determina la relación de parentesco entre ellos, es una ley que se aplica en el nombre del Padre. De forma parecida, la ley que repudia el deseo de la hija por la madre y por el padre exige que la niña acepte el emblema de la maternidad y preserve las reglas del parentesco. De esta manera, tanto la posición masculina como la femenina se establecen por leyes prohibitivas, que crean géneros culturalmente inteligibles, pero únicamente a través de la creación de una sexualidad inconsciente que reaparece en el ámbito de lo imaginario.

Desde estos tres conceptos de género, en que tres figuras claves de la cultura contemporánea lo consideran una performática, una ficción, interesada en regular la economía productiva de los cuerpos y restrictiva de la mujer centralmente, podemos entender que la manera de articularse de Mistral como sujeto fue "menos que uno y 
doble", como señala Homi Bhabha al hablar del sujeto postcolonial, fragmentado en menos que uno, es decir, con muy poco poder sobre sus relaciones, y doble, es decir, sujeto a tener que esconderse en los múltiples rincones que le ofrece la cultura de su tiempo. Amparado en la sombra del Otro, se forma el ser postcolonial, sabiendo que no hay palabra ni acto suyo que pueda modificar los deseos y coerciones que imponen los poderes hegemónicos y también, en el caso de Mistral, por mestiza y por mujer, estereotipos de raza y de cultura étnica, a la par que los ya comentados estereotipos genérico-sexuales.

Mistral entonces juega con esos conceptos: primero, rechaza ser madre en su célebre "Poema del hijo", pero celebró la maternidad en otras mujeres, que tal vez no eran locas, porque se habían forzosamente adaptado al rol de madre .Pero Mistral respetaba ese lugar, tenía amor por su propia madre y dedicó poemas y textos muy verdaderos a ciertas madres. En sus cartas, además, a la hermana de Huidobro, carta de duelo por la muerte de la madre, Mistral le dice que comenzamos a morir cuando se muere la madre. En carta a Victoria Ocampo, la escritora se conduele de la argentina porque su idioma materno no coincidió con la lengua que le enseñaran sus institutrices, que fue el francés y posteriormente, el inglés. Mistral lo consideraba como una falla simbólica, aunque en realidad fue, para Victoria Ocampo, la gran carta que le sirvió para ocupar un lugar de prestigio en la intelectualidad argentina.

Más allá del error o la razón, cito estos comentarios como datos que aportan una pista en la constitución del sujeto mistraliano y su relación con lo materno.

La escritora creía que la madre jugaba un rol fuerte en la niñez, época en la que se modela la construcción del imaginario.

Creía firmemente que ella, que encontraba débil el imaginario chileno dominante, lo que dejaba para la mujer el carácter de "vencido", como escribe en el "Poema del Hijo", en el que renuncia a la maternidad como lugar.Poema que articula desde el momento de su escritura y tal vez, para siempre, inicia su ruptura amorosa con lo masculino.

Es escaso el papel que juega ese lugar en la poética mistraliana. No era, no fue el gran otro de la Mistral, quien no vio la pareja más que dentro de una concepción binaria castigadora para ella: en que la mujer, sirvienta y madre, semi analfabeta y muy ignorante, se hace esposa de quien la abandona, la deja, y ella con sus hijos se autodetermina, "condenándose al heroísmo", como dice Jorge Guzmán en su conocido artículo "Por hambre de su carne".

Mistral no vio héroes en su vida ni conceptual ni amorosa; vio seres que falibles y mal encasillados en los roles del gran conceptual, el creativo, el pensante, estructuran la figura a partir de la cual se ha elaborado la imagen del hombre de la raza latinoamericana. Admiró a algunos, como Amado Nervo, Rubén Darío, pero no les dio la épica estatura de héroes.

Pero es en Tala donde la escritora se libera de una conciencia represora y genera una voz disidente, que produce una tercera figura, la de una mujer que se deshace de todo y que señala: "quiso el amor soledades / como lobo silencioso. Se vino a cavar 
su casa/ en el valle más angosto/ y la huella le seguimos/ sin demandarle retorno... Y más adelante, escribe: "Nos sobran todas las cosas/ que teníamos por gozos: los labrantíos, las costas/ las anchas dunas de hinojos. / El asombro del amor/ acabó con los asombros" Y más aún: "Ya ni recuerdo cómo era / cuando viví con los otros / Quemé toda mi memoria / como hogar menesteroso. / Los tejados de mi aldea/ si vuelvo, no los conozco, / y el hermano de mis leches/ no me conoce tampoco. / Y no quiero que me hallen/ donde me escondí de todos/ antes hallen en el hielo/ el rostro huido del oso/ El muro es negro de tiempo/ el liquen del umbral, sordo, / y se cansa quien nos llame/ por el nombre de nosotros. // Atravesaré de muerta/ el patio de hongos morosos/ El me cargará en sus brazos/ en chopo talado y mondo:/ Yo miraré todavía / el remate de sus hombros./ La aldea que no me vio/ me verá cruzar sin rostro/ y sólo me tendrá el polvo/ volador, que no es esposo" (“La Dichosa” 207-208).

Han sido estudiadas las múltiples identidades con que desplazó Mistral su ser en su poesía, tanto por Guzmán, como por Marchant y Adriana Valdés. Es en este poemario, Tala, y más tarde en Lagar en donde ella elabora su ser de adulta, no perteneciente a ningún país, viviendo el amor como "un asombro que acabó con los asombros". Y finalmente, señala: "ya ni recuerdo como era... quemé toda mi memoria como hogar menesteroso."

Pobre le parece a Mistral su memoria; pobre, su historia. Duro el trabajo de ser dependiente y colonizada desde dentro. Débil, "menesteroso" el hogar de donde provino, y por cierto, señala que ya no hay retorno, desde donde ella está.

Dicho y hecho, murió en Estados Unidos en 1957, cerca de Doris Dana, su último amor.

La poeta elabora aquí el sentido de su ¿voluntario? exilio. "Atravesaré de muerta/ el patio de hongos morosos". Pero, podemos preguntarnos: ¿será este poema otro repliegue de la escurridiza identidad mistraliana?, o es éste un momento de dicha, un júbilo de encontrar su ser más allá de toda frontera, identidad, en donde ella transgenérica y transexual, señala que sólo la tendrá el polvo volador, no el esposo. Señala además que su aldea no le vio ni le verá el rostro. Esta nueva cara, adquirida, por la que lucha Mistral es la que al fin ha encontrado como modo de entenderse a sí misma y este modo es, sin lugar a dudas, la libertad, más allá de todo sectarismo, clasismo, racismo y generidad.

\section{Referencias}

Bhabha, Homi. El lugar de la cultura. Buenos Aires: Manantial, 1994. Medio impreso. Butler, Judith. El Género en disputa. Barcelona: Paidós, 2007. Medio impreso.

---. Gender trouble. New York/London: Routledge, 1990. Medio impreso.

Derrida, Jacques. La Escritura y la Diferencia, Barcelona: Anthropos, 1989. Medio impreso. 
---. La Gramatología. México: Siglo XXI, 1997. Medio impreso.

---. Márgenes de la Filosofía. Madrid: Cátedra, 1989. Medio impreso.

---. La Tarjeta Postal. México: Siglo XXI, 1986. Medio impreso.

Franco, Jean. "Loca y no loca. La cultura popular en la obra de Gabriela Mistral" En Releer hoy a Gabriela Mistral. Canadá: Université d' Ottawa, 1997. Medio impreso.

Guzmán, Jorge. Diferencias latinoamericanas. Stgo: Eds. del Departamento de Estudios Humanísticos. 1984. Medio impreso.

Lacan, Jacques. En El género en disputa. Barcelona: Paidós, 2007. Medio impreso.

Marchant, Patricio. Sobre árboles y madres. Santiago: Gato Murr, 1984. Medio impreso.

Mistral, Gabriela. Niña Errante. Barcelona: Lumen, 2009. Medio impreso.

---. Poesías Completas. Santiago: Andrés Bello, 2001. Medio impreso.

Molloy, Sylvia. Womens Writing in Latin America. Estados Unidos: Westview Press, 1992. Medio impreso.

Morales, Leonidas. La escritura de al lado. Géneros referenciales. Santiago: Cuarto Propio, 2001. Medio impreso.

Olea, Raquel. Como traje de Fiesta. Loca Razón en la Poesía de Gabriela Mistral. Santiago: Usach, 2009. Medio impreso.

Rubin, Gayle. "El tráfico de mujeres. Notas sobre la economía política del sexo". Revista Nueva Antropología 30 (noviembre 1986). 95-145. México: Universidad Nacional Autónoma de México. Medio impreso.

Wittig, Monique. en El género en disputa. Barcelona: Paidós 2007. Medio impreso.

Recibido: 05 agosto 2013

Aceptado: 27 agosto 2013 